\title{
PROFESIONALISME GURU PENDIDIKAN AGAMA ISLAM DALAM MEMBENTUK RELIGIUSITAS SISWA KELAS IV DI SDN 2 PENGARAYAN
}

\begin{abstract}
Syarnubi

UIN Raden Fatah Palembang email:

syarnubi@radenfatah.ac.id

This study aims to describe and analyze critically the professionalism of teachers in the form of PAI religiosity fourth grade students at SDN 2 Pengarayan. This research is a qualitative research taking the location of SDN 2 Pengarayan. Data collection are getting by observation, documentation and interIVews. Data analysis were carried out by examining all data, data reduction, data presentation, drawing conclusions and verifying data. Data checking is done by triangulation with two modes, namely using multiple sources and multiple methods.

The results of the study show: (1) PAI teachers in SDN 2 Pengarayan are professional, which is indicated by haIVng four competencies: pedagogic competency, personality competence, professional competence and social competence. (2) PAI teachers is forming the religiosity of fourth grade students in SDN 2 Pengarayan through five dimensions of religiosity (Belief, worship, appreciation, knowledge and experience), using habituation methods related to four competencies as follows : Pedagogical aspects: Prepare syllabus and lesson plans. Personality Aspect: Making the dhuhur prayer schedule in congregation and assistance, praying duha and reciting the Asmaul Husna. Professional Aspects: BATUHA (Read Write AlQur'an), PHBI (Commemoration of Islamic Day) and Muadzin. Social Aspects: Making Tambourine Music Group, Ramadhan pesantren and habit of greeting. (3) The obstacles faced by PAI teachers in forming the religiosity of students in SDN 2 Pengarayan are the limitations of place, time and superIVsors, the low support of parents when at home, the lack of harmonious cooperation between parents of students and the school, the cleanliness of places of worship become an obstacle in the implementation of prayer serIVces.
\end{abstract}

Keywords: Professionalism, PAI Teachers, Religiosity 


\section{PENDAHULUAN}

Pendidikan menurut Undang-undang Sistem Pendidikan Nasional Nomor 20 Tahun 2003 adalah usaha sadar dan terencana untuk mewujudkan suasana belajar dan proses pembelajaran agar peserta didik secara aktif mengembangkan potensi dirinya untuk memiliki kekuatan spiritual keagamaan, pengendalian diri, kepribadian, kecerdasan, akhlak mulia, serta keterampilan yang diperlukan dirinya, masyarakat bangsa dan negara. Pengembangan kompetensi diri peserta didik diharapkan untuk menyiapkan penerus bangsa ini siap menerima tantangan apa pun di masa yang akan datang.

Pendidikan dapat dipandang sebagai proses penting untuk memenuhi janji kemerdekaan. Pendidikan yang berkualitas akan mencetak generasi masa depan yang juga berkualitas. Sebagai contoh, pada 1960-an, Korea Selatan masih menjadi negara berkembang yang tidak diperhitungkan. Namun saat ini, Korea Selatan menjadi negara industri yang diperhitungkan dalam percaturan global. Korea selatan tidaklah mungkin bisa mengejar ketertinggalan tanpa kerja keras lewat sektor pendidikan. Masih banyak contoh lain yang menunjukkan bahwa pendidikan adalah kunci kemajuan sebuah bangsa. Kemajuan bangsa Eropa merupakan efek dari Reinessance (zaman pembaruan Eropa) yang mendorong kebebasan berpikir. Selanjutnya, muncullah masyarakat terdidik yang mendorong kemajuan bangsa Eropa. (Munif Chatib, 2012: xii)

Pendidikan (sekolah) merupakan salah satu faktor pembentuk religiusitas seseorang. Pendidikan di sekolah terutama pendidikan agama mempunyai peranan yang sangat besar di dalam membentuk religiusitas seseorang. Pengalaman agama yang ia peroleh (pernah dilakukan) disekolah mempunyai dampak yang cukup besar dalam praktek keagamaan seseorang di dalam kehidupan sehari-hari. Fungsi utama sekolah adalah sebagai media untuk merealisasikan pendidikan berdasarkan tujuan pemikiran, akidah, syari'at demi terwujudnya penghambaan diri kepada Allah serta sikap mengesakan Allah dan mengembangkan segala bakat ayau potensi manusia sesuai dengan fitrahnya sehingga manusia terhindar dari berbagai penyimpangan. 
Pendidikan Agama Islam sangat berperan dalam usaha membentuk manusia yang beriman dan bertaqwa pada Allah SWT, menghargai dan mengamalkan ajaran agama dalam bermasyarakat, berbangsa dan bernegara. Maka dari itu Pendidikan Agama harus diajarkan pada anak sejak dini. Firman Allah :

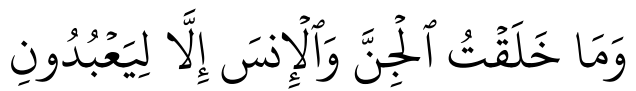

Artinya:

Dan aku tidak menciptakan jin dan manusia melainkan supaya mereka menyembah-Ku. (QS. Adz-Dzariyat: 56)

Dalam upaya mencapai pendidikan agama Islam berkualitas, harus dimulai dengan guru pendidikan agama Islam yang berkualitas. Upaya meningkatkan kualitas pendidikan agama Islam tanpa memperhitungkan guru agama Islam secara nyata, hanya akan menghasilkan satu fatamorgana atau sesuatu yang semu dan tipuan belaka.

Guru pendidikan agama Islam merupakan unsur utama dalam keseluruhan proses pendidikan agama Islam. Tanpa guru, pendidikan hanya akan menjadi slogan muluk karena segala bentuk kebijakan dan program pada akhirnya akan ditentukan oleh kinerja pihak yang berada di garis terdepan yaitu guru. Sosok guru yang berakhlak kuat dan cerdas diharapkan mampu mengemban amanah dalam mendidik peserta didiknya. Untuk menjadi guru atau tenaga pendidik yang handal harus memiliki seperangkat kompetensi. Kompetensi utama yang harus melekat pada tenaga pendidik adalah nilai-nilai keamanahan, keteladanan dan mampu melakukan pendekatan pedagogis serta mampu berfikir dan bertindak tegas.

Ditengah-tengah perkembangan dunia yang begitu cepat dan semakin canggih, prinsip-prinsip untuk membangun etika, nilai dan akhlak peserta didik tetap harus dipegang. Akan tetapi perlu dilakukan dengan cara yang berbeda atau kreatif sehingga mampu mengimbangi perubahan kehidupan. Guru harus memiliki kemitmen yang kuat dalam melaksanakan pendidikan secara holistik yang berpusat pada potensi dan kebutuhan peserta didik. Pendidik juga harus mampu menyiapkan peserta didik untuk bisa menangkap peluang dan kemajuan dunia dengan perkembangan ilmu dan teknologi. 
Problem kemerosotan moral akhir-akhir ini menjangkit sebagian generasi muda. Gejala kemerosotan moral antara lain diindikasikan dengan merebaknya kasus penyalahgunaan narkoba, pergaulan bebas, kriminalitas kekerasan dan aneka perilaku kurang terpuji lainnya. Dilain pihak, tidak sedikit dari generasi muda yang gagal menampilkan akhlak terpuji (akhlak mahmudah) sesuai harapan orang tua. Kesopanan, sifat-sifat ramah, tenggang rasa, rendah hati, suka menolong, solidaritas sosial dan sebagainya yang merupakan jati diri bangsa berabad-abad seolah-olah kurang begitu melekat secara kuat dalam diri mereka.

Selama ini pendidikan yang dikembangkan lebih menekankan pada aspek kognitif saja, kurang memperhatikan sisi afektif dan psikomotorik siswa. Pelajaran agama seringkali dimaknai secara dangkal dan tekstual. nilai-nilai agama yang ada hanya dihafal dan tidak diamalkan, padahal nilai-nilai religiusitas tidak hanya tampak ketika seseorang melakukan praktek ritual peribadatan saja, seperti sholat, berdo'a, puasa, zakat dan haji. Namun nilai religiusitas nampak pada semua aktifitas keseharian seseorang yang mencerminkan unsur aqidah, ibadah dan akhlak.

Pengelolaan pendidikan yang tidak serius akan memberikan dampak negatif terhadap keberhasilan pendidikan. Dewasa ini pendidikan di Indonesia belum dapat membawa kepada penyelesaian masalah-masalah yang berkaitan akhlak maupun moralitas bangsa.

UU Nomor 14 Tahun 2005 tentang Sistem Pendidikan Nasional (Sisdiknas) Pasal 3 menyatakan bahwa pendidikan nasional berfungsi mengembangkan kemampuan dan membentuk watak serta peradaban bangsa yang bermanfaat dalam rangka mencerdaskan kehidupan bangsa, bertujuan untuk berkembangnya potensi siswa agar menjadi manusia yang beriman dan bertakwa kepada Tuhan Yang Maha Esa, berakhlak mulia, sehat, berilmu, cakap, kreatif, mandiri, dan menjadi warga negara yang demokratis serta bertanggung jawab.

Disini peranan guru pendidikan agama Islam sangatlah penting untuk menanamkan pendidikan akhlak pada siswa. Guru sebagai suri tauladan bagi siswa-siswanya harus memberikan contoh akhlak yang baik sehingga bisa mencetak dan membentuk generasi yang memiliki kepribadian baik pula. 
Pembinaan akhlak peserta didik disekolah oleh guru pendidikan agama islam merupakan upaya yang dilakukan dalam rangka pembentukan akhlak peserta didik yang identik dengan pembinaan akhlak mulia. Metode keteladanan dan pembiasaan yang dilakukan oleh guru pendidikan agama islam sangat berpengaruh terhadap kejiwaan siswa. Jika nilai religius sudah tertanam dalam diri siswa dan di pupuk dengan baik maka dengan sendirinya akan tumbuh menjadi pribadi yang baik.

Pemilihan SDN 2 Pengarayan sebagai objek penelitian karena ada hal yang menarik dengan suasana religi yang ada di SDN 2 Pengarayan. Penulis heran, bagaimana bisa sekolah umum (negeri) yang tidak berlatar belakang agama namun tercermin suasana keagamaan yang tidak kalah jauh dengan sekolah berasrama (boarding school) atau sekolah-sekolah yang berlatar belakang agama atau sekolah-sekolah yang berlabel sekolah Islam Terpadu (IT). Padahal pelajaran Pendidikan Agama Islam (PAI) yang ada di SDN 2 Pengarayan tidak jauh berbeda dengan sekolah negeri pada umumnya, yakni hanya terbatas 2 jam pelajaran dalam seminggu. Materi yang ada pun merupakan satu kesatuan yang utuh antara materi ibadah, qur'an-hadits, akhlak, sejarah kebudayaan Islam yang tergabung menjadi satu mata pelajaran yaitu Pendidikan Agama Islam (PAI).

Hal tersebut di atas dibuktikan dengan banyaknya siswi putri yang berjilbab, kegiatan sholat dhuha yang berjalan tertib, kegiatan sholat jama'ah dhuhur dan kegiatan keagamaan lainya. Terlintas dalam pikiran penulis, inilah sekolah negeri yang bernuansa madrasah. Hal ini melatarbelakangi keinginan penulis untuk mengetahui lebih jauh, bagaimana peran guru PAI dalam membentuk akhlaksiswa, sehingga para siswa menjalankan ibadah keagamaan yang di dasari oleh kesadaran dan kemauan dari para siswanya, bukan merupakan paksaan dari gurunya. Selain itu, penulis juga ingin mengetahui lebih jauh terkait dengan akhlak para siswa apakah hanya sebatas pada kegiatan agama secara formal saja (dapat diamati dan tampak atau terlihat oleh mata) atau nilai-nilai akhlak sudah membentuk dalam diri siswa dan terwujud pada perilaku sehari-hari siswa seperti kejujuran, kedisiplinan, ketaatan, kepatuhan dan lain sebagainya. Oleh sebab itu penelitian yang berkaitan dengan peran guru pendidikan agama 
islam dalam pembentukan religiusitas siswa di SDN 2 Pengarayan ini sangat penting dilakukan.

\section{METODE PENELITIAN}

Dalam penulisan ini peneliti menggunakan pendekatan kualitatif dimana dalam penelitian ini lebih menekankan pada makna dan proses daripada hasil suatu aktilVtas, serta data yang dihasilkan berupa data deskriptif bukan angka-angka. Sedang jenis penelitian yang dipakai oleh peneliti adalah jenis deskriptif kualitatif yang mempelajari masalah-masalah yang ada serta tata cara kerja yang berlaku.

Tempat penelitian yang akan peneliti gunakan adalah SDN 2 Pengarayan, pemilihan SDN 2 Pengarayan sebagai objek penelitian karena ada hal yang menarik dengan suasana religi yang ada di SDN 2 Pengarayan. Penulis heran, bagaimana bisa sekolah umum (negeri) yang tidak berlatar belakang agama namun tercermin suasana keagamaan yang tidak kalah jauh dengan sekolah berasrama (boarding school) atau sekolah-sekolah yang berlatar belakang agama atau sekolah-sekolah yang berlabel sekolah Islam Terpadu (IT). Sedangkan Informan dalam penelitian adalah orang atau pelaku yang benar-benar tahu dan menguasai masalah, serta terlibat lansung dengan masalah penelitian. Informan dalam penelitian ini yaitu guru yang mengampu mata pelajaran PAI di SDN 2 Pengarayan kelas IV adalah Hindun, S.Pd.I, pengalaman mengajar sudah 11 tahun. Sertifikasi pada tanggal 17 November 2016.

Penelitian ini menggunakan teknik pengumpulan data yang meliputi observasi, wawancara, dan dokumentasi. Analisis data dilakukan dengan menelaah seluruh data, reduksi data, penyajian data, penarikan kesimpulan dan verifikasi terhadap data yang berhasil dikumpulkan. Pemeriksaan data dilakukan dengan trianggulasi dengan dua modus, yakni menggunakan sumber ganda dan metode ganda. 


\section{HASIL PENELITIAN}

\section{A. Profesionalisme Guru PAI di SDN 2 Pengarayan}

Guru yang mengampu mata pelajaran PAI di SDN 2 Pengarayan kelas IV adalah Hindun, S.Pd.I, pengalaman mengajar sudah 11 tahun. Sertifikasi pada tanggal 17 November 2016. Berdasarkan hasil wawancara bersama dengan Ibu Hindun beliau berpendapat bahwa, profesionalisme adalah, "Melakukan tugas atau pekerjaan sesuai dengan kemampuan (keahlian). Maksud dari penjelasan di atas adalah seorang guru bekerja atau bertugas sesuai dengan keahlian atau kemampuan dan mempunyai ilmu tentang kependidikan yang ditunjukkan dengan adanya legalitas ijazah tertentu." (Hasil wawancara dengan Ibu Hindun pada hari Selasa tanggal 9 September 2018)

Untuk mengetahui kompetensi yang dimiliki oleh guru PAI SDN 2 Pengarayan dapat dilihat di dalam tabel sebagai berikut:

\begin{tabular}{|l|}
\hline Hindun, S.Pd.I \\
\hline Pedagogik
\end{tabular}

Dari hasil observasi pembelajaran pada hari Senin tanggal 15 September 2018 dapat dilihat beberapa kompetensi yang dilakukan Ibu Hindun dalam kompetensi pedagogik

diantaranya sebagai berikut:

a. Mampu mengkonsep pembelajaran dengan baik, yang ditunjukkan dengan membuat Silabus dan Rencana Pelaksanaan Pembelajaran (RPP).

b. Keterampilan bertanya dikuasai dengan baik, terlihat dalam pembelajaran dengan adanya penyebaran, pemindahan giliran dan pemberian waktu berpikir.

c. Mengadakan variasi metode sesuai dengan materi yang diajarkan. Salah satunya menggunakan metode demonstrasi, beliau langsung melibatkan seluruh peserta didik seperti dalam pembelajaran salat.

d. Keterampilan memberi penguatan beliau menggunakan penguatan verbal sekaligus non verbal yakni mendekati peserta didik memegang 
bahunya dengan mengucapkan bagus itu terlihat dalam pembelajaran thaharah.

e. Mampu mengelola kelas dengan baik, itu terlihat proses pembelajaran berjalan dengan efektif dan menyenangkan.

\section{Kepribadian}

Dari hasil Observasi pembelajaran Rabu 24 September 2018 yang penulis lakukan, dapat dilihat beberapa kompetensi yang dimiliki Ibu Hindun dalam kompetensi kepribadian

diantaranya sebagai berikut:

a. Ibu Hindun mempunyai kepribadian yang mantap, stabil, arif dan berwibawa itu terlihat emosinya terjaga ketika menghadapi peserta didik yang bermasalah dalam proses pembelajaran di kelas. Mempunyai etos kerja yang tinggi dalam meningkatkan kualitas peserta didik, mempunyai rasa bangga menjadi guru yang senantiasa tiada hentihentinya memberikan pengarahan dan bimbingan terhadap peserta didik.

b. Terbuka menerima saran dan kritik dari peserta didik, itu terlihat dalam proses pembelajaran beliau memberikan waktu luang atau kesempatan untuk memberikan pendapat atau ide yang terkait dengan memajukan dan meningkatkan dalam proses pembelajaran.

c. Dapat menjadi tauladan bagi peserta didik dengan menampilkan akhlak yang baik di lingkungan sekolah maupun di masyarakat.

\section{Profesional}

Dari hasil pengamatan yang penulis lakukan, dapat dilihat beberapa kompetensi yang dilakukan Ibu Hindun dalam kompetensi professional diantaranya sebagai berikut:

a. Memiliki pengetahuan yang luas dan mendalam terhadap mata pelajaran yang beliau ampu. Itu terlihat dalam proses pembelajaran, beliau mampu mengkaitkan ilmu fiqih dengan disiplin ilmu lain. Contoh, waktu salat dikaitkan dengan ilmu fisika, puasa dengan ilmu kesehatan, gerakan salat dengan ilmu kesehatan dan jual beli dengan ilmu ekonomi.

b. Memahami jenis-jenis materi pembelajaran, yaitu dalam 
mempertimbangkan validitas, keberartian, relevansi, kemenarikan dan kepuasan materi yang akan diajarkan.

c. Mengurutkan dan mengorganisasikan materi pembelajaran.

\section{Sosial}

Dari hasil pengamatan yang penulis lakukan, dapat dilihat beberapa kompetensi yang dilakukan Ibu Hindun dalam kompetensi social diantaranya sebagai berikut:

a. Mampu berinteraksi dengan baik dengan kepala sekolah, guru-guru, peserta didik, karyawan dan masyarakat. Seperti saling bertukar pendapat dengan guru mata pelajaran yang lain ketika jam istirahat, berbagi cara mengatasi peserta didik yang bermasalah di dalam kelas, bekerja sama dengan Waka Kurikulum terkait dengan penjadwalan salat berjamaah dan salat duha.

b. Selain itu juga penulis mendapat keterangan Ibu Hindun aktif dalam beberapa kegaitan yang ada di masyarakat, pengajian rutin, mengikuti kegiatan Isra' Mi'raj dll, dan aktif dalam kegaitan sosial seperti kerja bakti dll.

B. Upaya yang dilakukan oleh guru PAI dalam membentuk religiusitas siswa kelas IV di SDN 2 Pengarayan

Pertama, dimensi keyakinan. Berdasarkan wawancara dan pengamatan yang penulis lakukan, cara yang dilakukan oleh guru PAI SDN 2 Pengarayan dalam meyakinkan peserta didik dengan menanamkan nilai-nilai agama yaitu dengan akidah Islam.

Cara yang dilakukan oleh guru PAI SDN 2 Pengarayan dalam membentuk keyakinan peserta didik adalah sebagai berikut:

1. Salat. Peserta didik khidmat dalam menjalankan ibadah salat

2. Asmaul Husna. Peserta didik berdo'a dengan menggunakan nama-nama Allah

3. BATUHA. Peserta didik dapat menghayati makna dari ayat Al-Qur'an 
4. PHBI. Peserta didik dapat memahami makna dari peringatan hari besar Islam

5. Muadzin. Peserta didik mamahami bahwa panggilan salat telah diperdengarkan.

6. Group musik rebana. Peserta didik memahami makna dari syair-syair yang di lantunkan

7. Pesantren kilat. Peserta didik didoktrin untuk menjadi manusia yang religius melalui kegiatan-kegiatan yang dapat membentuk religius peserta didik. Seperti kultum (kuliah tujuh menit) yang disampaikan setelah salat berjamaah.

8. Mengucapkan salam. Peserta didik dapat memahami makna yang terkandung dalam pengucapan salam yakni dapat mempererat silaturahim.

Kedua, dimensi peribadatan atau praktek agama. Dalam hal ini guru PAI SDN 2 Pengarayan memberikan buku aktivitas kegiatan keagamaan yang terkait dengan ibadah seperti: puasa, salat duha, salat malam, salat berjamaah dan tadarus. Sehingga dengan demikian peserta didik akan selalu beribadah, baik di sekolah maupun di rumah.

Ketiga, dimensi pengetahuan. Berdasarkan hasil wawancara dan pengamatan yang penulis lakukan upaya yang dilakukan oleh guru PAI SDN 2 Pengarayan untuk meningkatkan pengetahuan peserta didik dengan cara membuat kegiatan ilmiah di luar kelas. Seperti mengadakan pelatihan baca tulis huruf alQur'an, ini dilakukan agar peserta didik dapat membaca Al-Qur'an dengan baik dan benar. Mengadakan peringatakan hari besar Islam seperti Nuzul Qur'an, Isra' Mi'raj. Ini dilakukan be rtujuan untuk menambah pengetahuan peserta didik dan mengetahui makna dari Nuzul Qur'an dan Isra'Mi'raj tersebut.

Keempat, dimensi pengalaman. Berdasarkan hasil wawancara dan pengamatan yang penulis lakukan, penulis melihat peserta didik kelas IV di SDN 2 Pengarayan sudah mampu beribadah dengan ikhlas tanpa harus diawasi dan diperintah oleh guru PAI SDN 2 Pengarayan. Ada beberapa cara yang dilakukan guru PAI SDN 2 Pengarayan yang terkait dengan profesionalisme guru dalam membentuk religiusitas diantaranya dengan dengan metode pembiasaan melalui 
program kerja yang terkait empat kompetensi dengan indikator sebagai berikut: (Dokumentasi, diambil dari data program kerja bidang keagamaan SDN 2 Pengarayan, pada hari Kamis 20 September 2018)

\begin{tabular}{|c|c|c|c|}
\hline No & $\begin{array}{l}\text { Program } \\
\text { Kerja }\end{array}$ & $\begin{array}{c}\text { Standar } \\
\text { kompetensi }\end{array}$ & Kompetensi Dasar \\
\hline 1 & $\begin{array}{l}\text { Salat berjamaah } \\
\text { dan } \\
\text { pendampingan }\end{array}$ & $\begin{array}{l}\text { Melaksanakan } \\
\text { tata cara salat } \\
\text { berjamaah }\end{array}$ & $\begin{aligned} \text { 1.1 } & \begin{array}{l}\text { Menjelaskan keutamaan } \\
\text { salat berjamaah }\end{array} \\
\text { 1.2 } & \begin{array}{l}\text { Menjelaskan tata cara } \\
\text { menjadi makmum yang baik }\end{array}\end{aligned}$ \\
\hline 2 & $\begin{array}{l}\text { Pembacaan } \\
\text { nadham Asmaul } \\
\text { Husna }\end{array}$ & $\begin{array}{l}\text { Memahami } \\
\text { nadham Asmaul } \\
\text { Husna }\end{array}$ & $\begin{array}{llr}2.1 & \text { Menjelaskan } & \text { keutamaan } \\
& \text { Asmaul Husna } & \\
\text { 2.2 } & \text { Menyebutkan } & \text { nadham } \\
& \text { Asmaul Husna } & \\
\end{array}$ \\
\hline 3 & $\begin{array}{l}\text { BATUHA (Baca } \\
\text { Tulis Huruf Al- } \\
\text { Qur'an) }\end{array}$ & $\begin{array}{l}\text { Melaksanakan } \\
\text { tata cara } \\
\text { membaca Al- } \\
\text { Qur'an }\end{array}$ & $\begin{array}{l}\text { 3.1 } \begin{array}{l}\text { Menjelaskan hukum tajwid } \\
\text { dalam membaca Al-Qur'an }\end{array} \\
\text { 3.2 } \begin{array}{l}\text { Menerapkan hukum tajwid } \\
\text { dalam membaca Al-Qur'an }\end{array}\end{array}$ \\
\hline 4 & $\begin{array}{l}\text { PHBI (Peringatan } \\
\text { Hari Besar Islam) }\end{array}$ & $\begin{array}{l}\text { Memahami hari } \\
\text { besar Islam }\end{array}$ & $\begin{array}{llr}4.1 & \begin{array}{l}\text { Menjelaskan } \\
\text { hari besarIslam }\end{array} & \text { keutamaan } \\
\text { 4.2 } & \begin{array}{l}\text { Menjelaskan } \\
\text { memperingati hari besar }\end{array} \\
& \text { hemgnya } \\
& \text { Islam } & \\
\end{array}$ \\
\hline 5 & Muadzin & $\begin{array}{l}\text { Melaksanakan } \\
\text { tata cara adzan }\end{array}$ & 5.1 Menjelaskan taat cara adzan \\
\hline 6 & $\begin{array}{l}\text { Pembuatan group } \\
\text { musik rebana }\end{array}$ & $\begin{array}{l}\text { Memahami syair- } \\
\text { syair Islami }\end{array}$ & $\begin{array}{l}\text { 6.1 Memberikan contoh syair- } \\
\text { syair Islami }\end{array}$ \\
\hline 7 & $\begin{array}{l}\text { Pesantren kilat } \\
\text { ramadhan }\end{array}$ & $\begin{array}{l}\text { Memahami } \\
\text { lingkungan yang } \\
\text { Islami }\end{array}$ & $\begin{array}{l}\text { 7.1 } \begin{array}{l}\text { Menjelaskan lingkungan } \\
\text { yang baik } \\
\text { 7.2 } \\
\text { Memberikan contoh } \\
\text { lingkungan yang baik }\end{array} \\
\end{array}$ \\
\hline 8 & $\begin{array}{l}\text { Mengucapkan } \\
\text { salam }\end{array}$ & $\begin{array}{l}\text { Mendeskripsikan } \\
\text { akhlak yang baik }\end{array}$ & $\begin{array}{l}\text { 8.1 } \begin{array}{l}\text { Menjelaskan akhlak yang } \\
\text { baik }\end{array} \\
\text { 8.2 } \begin{array}{l}\text { Memberikan contoh akhlak } \\
\text { yang baik. }\end{array}\end{array}$ \\
\hline
\end{tabular}

kelima, dimensi penghayatan. Berdasarkan wawancara dan pengamatan yang penulis lakukan, upaya yang dilakukan oleh guru PAI SDN 2 Pengarayan agar peserta didik dapat menghayati aktiIVtas keagamaan yang telah mereka lakukan dengan cara memberikan pemahaman agama sesuai dengan nilainya seperti keutamaan-keutamaan ibadah sunnah yang telah mereka lakukan, seperti: salat berjmaaah, salat duha dan puasa dan ibadah-ibadah sunnah lainnya. 
Ini dilakukan agar peserta didik dapat menghayati apa yang telah mereka lakukan dalam kehidupan sehari-hari.

Adapun untuk melihat penghayatan peserta didik adalah sebagai berikut:

1. Salat. Khidmat dalam menjalankan ibadah salat

2. Adzan. Ketika adzan dzuhur berkumandang mereka pergi ke musola, mengikuti salat dzuhur berjamaah dengan khidmat dan tertib'. Seperti yang dikatakan oleh Ainun siswa kelas IV A SDN 2 Pengarayan, mengatakan: "Ketika adzan dzuhur berkumandang saya langsung ke musola, bukan takut karena guru atau dihukum akan tetapi saya lakukan itu, berdasarkan hati nurani saya karena panggilan salat sudah dikumandangkan". (Wawancara dengan Ainun Siswa Kelas IV A SDN 2 Pengarayan pada hari Jum'at tanggal 21 September 2018 )

3. Asmaul Husna. Peserta didik mampu memaknai nama-nama Allah

4. BATUHA. Peserta didik memahami makna dari ayat al-Qur'an yang ia baca.

5. PHBI. Peserta didik memahami makna dari peringatan hari besar Islam

6. Group musik rebana. Peserta didik dapat melantunkan syair-syair lagu Islami dan dapat mengambil makna yang terkandung dalam lagu-lagu Islami tersebut.

7. Pesantren kilat. Dengan pembiasaaan lingkungan yang baik, peserta didik akan terbiasa dengan hal yang baik.

8. Mengucapkan salam. Peserta didik mengucapkan salam ketika bertemu guru, orang tua dan sahabatya.

C. Hambatan (kendala) yang di hadapi oleh guru PAI dalam membentuk religiusitas siswa kelas IV SDN 2 Pengarayan

Dalam menerapkan suatu program kerja tentunya akan mengalami berbagai kendala yang akan ditemui demikian juga guru PAI dihadapkan dengan beberapa permaslahan yang menjadi kendala dalam membentuk religiusitas siswa kelas IV SDN 2 Pengarayan.

Adapun hambatan (kendala) yang dialami guru PAI dalam membentuk religiusitas siswa kelas IV di SDN 2 Pengarayan adalah sebagai berikut: 
a. Keterbatasan tempat, waktu dan tenaga pengawas yang harus mengawasi peserta didik kelas IV yang mencapai 144 peserta didik.

b. Rendahnya dukungan orang tua dalam membentuk religius siswa ketika dirumah anaknya kurang diperhatikan karena disibukkan oleh pekerjaan yang menyebabkan pengawasan dari orang tua tidak ada ketika anak berada dirumah.

c. Belum adanya kerjasama yang harmonis antara orang tua siswa dengan pihak sekolah untuk saling membantu dan mencari metode yang paling tepat dalam menangani anak-anak yang tergolong nakal, karena orang tua siswa merasa telah memberi tanggung jawab penuh kepada sekolah, sehingga guru PAI sulit untuk mengetahui keadaan siswa sewaktu di rumah, dan hal itu dapat menghambat kinerja guru PAI dalam membentuk religiusitas siswa.

d. Kebersihan tempat beribadah yang menjadi kendala dalam pelaksanaan ibadah salat.

\section{KESIMPULAN}

Berdasarkan hasil wawancara, observasi, dan dokumentasi serta penganalisisan data yang dilakukan, penulis dapat mengambil beberapa kesimpulan tentang profesionalisme guru PAI dalam membentuk religiusitas siswa kelas IV di SDN 2 Pengarayan. Adapun kesimpulan tersebut sebagai berikut:

1. Guru PAI di SDN 2 Pengarayan sudah profesional, yang ditunjukkan dengan memiliki empat kompetensi yakni: kompetensi pedagogik, kompetensi kepribadian, kompetensi profesional dan kompetensi sosial.

2. Cara yang dilakukan oleh guru PAI dalam membentuk religiusitas siswa kelas IV di SDN 2 Pengarayan melalui lima dimensi keberagamaan (keyakinan, peribadatan, penghayatan, pengetahuan dan pengalaman), menggunakan metode pembiasaan yang tertuang dalam program kerja terkait dengan empat kompetensi adalah sebagai berikut: Aspek Pedagogik: Menyiapkan Silabus dan RPP (Rencana Pelaksanaan Pembelajaran). Aspek Kepribadian: 
Pembuatan jadwal salat dzuhur berjamaah dan pendampingan, salat duha dan pembacaan nadham Asmaul Husna. Aspek Profesional: BATUHA (Baca Tulis Hururf Al-Qur'an), PHBI (Peringatan Hari Besar Islam) dan Muadzin. Aspek Sosial: Pembuatan Group Musik Rebana, pesantern Kilat Ramadhan dan pembiasaan mengucapkan salam.

3. Hambatan (kendala) yang di hadapi oleh guru PAI dalam membentuk religiusitas siswa kelas IV SDN 2 Pengarayan adalah keterbatasan tempat, waktu dan tenaga pengawas, rendahnya dukungan orang tua dalam membentuk religius siswa ketika dirumah, belum adanya kerjasama yang harmonis antara orang tua siswa dengan pihak sekolah, Kebersihan tempat beribadah yang menjadi kendala dalam pelaksanaan ibadah salat. 


\section{DAFTAR PUSTAKA}

A. Partanto, Pius dan M. Dahlan Al Barry , Kamus Ilmiah Populer, Surabaya: Akola, 1994

Aliah B. Purwakania Hasan, Psikologi Perkembangan Islami, Jakarta: PT Raja Grafindo Persada, 2006

Alma, Buchari, Guru Profesional Menguasai Metode dan Terampil Mengajar, Bandung: Alfabeta, 2008

Arifin, Muzayyin, Filsafat Pendidikan Islam, Jakarta: PT Bumi Aksara, 2009

Arikunto, Suharsimi, Prosedur Penelitian Suatu Pendekatan Praktek, Jakarta: Rineka Cipta, 2002

Bugin, Burhan, Analisis dan Penelitian Kualitatif, Jakarta: PT. Raja Grafindo Persada, 2005 , Penelitian Kualitatif Komunikasi, Kebijakan Publik, Dan Ilmu Sosial lainnya, Jakarta: Kencana, 2007

Danim, Sudarman, Inovasi Pendidikan, Upaya Peningkatan Profesionalisme Tenaga Kependidikan, Bandung: CV. Pustaka Setia, 2002

Depdikbud, Kamus Besar Bahasa Indonesia, Yogyakarta: Balai Pustaka, 1990.

E. Mulyasa, Standar Kompetensi dan Sertifikasi Guru, Bandung: PT Remaja Rodaskarya, 2008 , Menjadi Guru Profesional Menciptakan Pembelajaran Kreatif dan Menyenangkan, Bandung: PT Remaja Rosdakarya, 2008

Herdananto, Bagus, Menjadi Guru Bermoral Profesional Disertai Peraturan Pemerintah Tentang Sertifikasi Guru, Yogyakarta: Kreasi Wacana, 2009

Harefa, Andrias, Membangkitkan Roh Profesionalisme, Jakarta: Gramedia:1999

Husaini Usman dan Purnomo Setiadi Akbar, Metodologi Penelitian Sosial, Jakarta: Bumi Aksara, 1994

Jalaluddin, Psikologi Agama, Memahami perilaku keagamaan dengan mengaplikasikan prinsip-prinsip psikologi, Jakarta: PT. Raja Grafindo Persada, 2008 
Jamaludin Ancok \& Fuad Nashori Suroso, Psikologi Islami, Yogyakarta: Pustaka Pelajar, 2008

Kusnandar, Guru Profesional Implementasi Kurikulum Tingkat Satuan Pendidikan (KTSP) dan Persiapan Menghadapi Sertifikasi Guru, Jakarta: PT Grapindo Persada, 2007

La Susilo Umar Tirtarahardja, Pengantar Pendidikan, Jakarta: PT Rineka Cipta, 2005

Meleong, Lexi J. Metodologi Penelitian Kualitatif, Bandung: Remaja Rosda Karya, 2006 , Metode Penelitian Kualitatif, Bandung: Remaja Rosdakarya, 1994

Miles, Mathew B, dkk, Analisis Data Kualitatif, Jakarta: UI Press, 1993

Muhaimin, Wacana Pengembangan Pendidikan Islam, Yogyakarta: Pustaka Pelajar, 2004

Mulkhan Abdul Munir, Religiusitas Iptek Rekontruksi Pendidikan dan Tradisi Pesantren, Yogyakarta: Fak. Tarbiyah UIN-SUKA bekerja sama dengan Pustaka Pelajar, 1998

Muslich, Mansur, Sertifikasi Guru menuju Profesionalisme Pendidik, Jakarta: Bumi Aksara, 2007

Naim, Ngainun, Rekontruksi Pendidikan Nasional, Membangun Paradigma Yang mencerahkan, Yogyakarta: Teras, 2009

Nasrori, Fuad, dkk., Mengembangkan Kreatifitas dalam Perspektif Psikologi Islam, Yogyakarta: Menera Kudus, 2002

Nazarudin, Manajemen Pembelajaran Implementasi Konsep, Karakteristik dan Metodologi Pendidikan Agama Islam di Sekolah Umum, Yogyakarta: Teras, 2007

Nurdin, Muhammad, Kiat Menjadi Guru Profesional Yogyakarta: Prismasophie, 2004

Nurdin, Syafruddin, Guru Profesional dan Implementasi Kurikulum, Jakarta: Ciputat Pers, 2002

Nizar Samsul Al- Rasyidin, Pendekatan Historis, Teoritis dan Praktis Filsafat Pendidikan Islam, Jakarta: PT. Ciputat Press, 2005 
Sudjana, nana, Dasar-dasar Proses Belajar Mengajar, Bandung: Sinar Baru Algesindo, 2005

Sugiyono, Metode Penelitian Pendidikan (Pendekatan Kuantitatif, Kualitatif, dan $R \& D)$, Bandung: Alfabeta, 2008

Suparlan, Guru Sebagai Profesi, Yogyakarta: Hikayat Publising, 2006

Syaiful Bahri Djaramah, Psikologi Belajar, Jakarta: PT Rineka Cipta, 2008

Undang-Undang Sistem Pendidikan Nasional, Yogyakarta: Pustaka Pelajar, 2009

Undang-Undang Guru dan Dosen, Yogyakarta: Pustaka Pelajar, 2009

Uhbiyati Nur Abu Ahmadi, Ilmu Pendidikan Islam, Jakarta: PT Rineka Cipta, 2001

Usman, Uzer, Menjadi guru Profesional, Bandung: PT Remaja Rodaskarya, 1995. 